\title{
A LEI 10.639 E A OBRIGATORIEDADE DO ENSINO DE HISTÓRIA E CULTURA AFRO- BRASILEIRA E AFRICANA: OUTRAS VOZES PARA O ENSINO DE FILOSOFIA
}

\author{
Edlene Pereira de Castro Silva* \\ Ricardo Ferreira Rocha* \\ Joelson Alves Onofre ${ }^{* * *}$
}

\begin{abstract}
Resumo: O presente texto apresenta algumas reflexões sobre o ensino de Filosofia e a Lei 10.639. Aborda questões referentes à inclusão desta lei no currículo escolar, bem como discute como os professores podem incluir a filosofia africana no currículo de Filosofia do ensino médio. Constitui-se numa perspectiva crítica e reflexiva com aporte bibliográfico pautando-se numa crítica acerca dos estudos no campo da Filosofia sobre relações étnico-raciais poucos difundidos e discutidos, principalmente no Brasil. As proposições levantadas e as questões problematizadas indicam que o ensino de Filosofia apresenta outras epistemologias, filosofias africanas que rompem com a perspectiva eurocêntrica do conhecimento, possibilitando novos saberes.
\end{abstract}

Palavras-chave: Currículo; Educação; Ensino; Filosofia Africana; Lei 10.639/03.

Resumen: El presente texto presenta algunas reflexiones sobre la enseñanza de la filosofía y la ley 10.639. Aborda cuestiones relacionadas con la inclusión de esta ley en el plan de estudios de la escuela, y discute cómo los maestros pueden incluir la filosofía africana en el plan de estudios de filosofía de la escuela secundaria. Constituye una perspectiva crítica y reflexiva con apoyo bibliográfico basado en una crítica sobre los estudios en el campo de la filosofía sobre las relaciones étnico-raciales que no están ampliamente difundidas y discutidas, principalmente en Brasil. Las propuestas planteadas y las preguntas problemáticas indican que la enseñanza de la filosofía presenta otras epistemologías, filosofías africanas que rompen con la perspectiva eurocéntrica del conocimiento, permitiendo nuevos conocimientos.

Palabras claves: Plan de estudios; Educación; Enseñando; Filosofía Africana; Ley 10.639/03.

\section{Introdução}

O presente artigo discorre sobre o ensino de Filosofia e a Lei 10.639/03, propondo investigar de que maneira a lei traz modificações no ensino, de modo a colaborar $e$

\footnotetext{
* Graduada em Filosofia pela Universidade Estadual de Feira de Santana - UEFS.

E-mail: edlenecastro03@gmail.com

** Graduado em Filosofia pela Universidade Estadual de Feira de Santana - UEFS.

E-mail: ricardo.fsa18@hotmail.com

**** Professor Assistente da Universidade Estadual de Santa Cruz - UESC. Membro do Grupo de Pesquisa Baobá: grupo de estudos em ancestralidade e pensamento de(s)colonial (IFBA).

E-mail: jaonofrecp@yahoo.com.br
}

legitimar os conteúdos afro-brasileiro e africano nos currículos de todos os níveis e modalidades de ensino no Brasil, pensando o espaço escolar como uma possibilidade de crítica e a movimentação dos conceitos, discutindo a pluralidade de pensamentos, dentre eles o pensamento africano $e$ afrobrasileiro e os olhares sobre o ensino de $\mathrm{Fi}$ losofia.

Percorrendo perspectivas do ensino de filosofia africana e oferecendo uma proximidade com o Outro, e consequentemente, com a imagem dos povos marginalizados e discriminados ao longo dos anos, propõe-

SILVA, Edlene Pereira de Castro; ROCHA, Ricardo Ferreira; ONOFRE, Joelson Alves. A Lei 10.639 $e$ a obrigatoriedade do ensino de história e cultura afro-brasileira e africana: outras vozes para o ensino de filosofia. Revista Sul-Americana de Filosofia e Educação. Número 32/33: nov. 2019 - out. 2020, p. 47-60. DOI: https://doi.org/10.26512/resafe.v1i32/33.35111 
se dialogar e caminhar rumo a uma educação a favor da diversidade.

O objetivo deste artigo é problematizar acerca da necessidade de se discutir o ensino de Filosofia nas escolas públicas, especificamente no ensino médio, fazendo uma relação com a Lei 10.639/03 na Educação Básica, que estabelece as diretrizes e bases da educação nacional, para incluir no currículo oficial da rede de ensino a obrigatoriedade da temática "História e Cultura Afro-Brasileira".

Neste sentido, a questão norteadora para as nossas reflexões surge a partir das leituras e proposições sobre o ensino de Filosofia e a supracitada Lei, questionando o caráter eurocêntrico do conhecimento, promovendo debates $e$ incursões teóricas que indiquem outras possibilidades de saberes no campo filosófico africano e o ensino de Filosofia, tendo como tarefa primordial desmistificar a ideia que existe apenas um tipo de conhecimento.

Assim sendo, faz-se necessário questionarmo-nos: até que ponto a lei 10.639/03 tem sido incluída nos currículos escolares das redes públicas e privadas de ensino? Quais outras epistemologias são apresentadas pela Filosofia e que, consequentemente, precisam também estar alinhadas ao seu ensino? Como os professores podem incluir a filosofia africana em suas aulas no ensino médio? De que forma trabalhar na escola a importância da filosofia africana para a quebra de paradigmas cristalizados que priorizam apenas a tradição filosófica grega? Enfim, essas interpelações nos provocam a repensar a escola como espaço da diversidade, pluralidade $e$ respeito às diferenças.
Discutir, portanto, o ensino de Filosofia na educação básica, considerando o contexto das novas abordagens e estudos acerca de uma filosofia africana é ampliar o repertório conceitual em que a filosofia africana assume um importante papel na construção de uma nova epistemologia. Desse modo, há de se contestar criticamente as teorias filosóficas tradicionais que desconsideram as demais filosofias existentes, como por exemplo, a filosofia africana.

É nessa perspectiva que a lei $10.639 / 03$ se insere quando modifica o art. 26- $\mathrm{A}^{4}$ da Lei 9.394/96 $\left(\mathrm{LDB}^{5}\right)$ estabelecendo a obrigatoriedade do ensino de História $e$ Cultura Afro-Brasileira. Para embasarmos a discussão acerca do ensino obrigatório da história da cultura afro-brasileira e africana na educação, recorremos a estudiosos que problematizam o ensino de Filosofia e a lei 10.639, a exemplo dos professores Alejandro Cerletti, Renato Noguera e Wanderson do Nascimento, além de outros pesquisadores que discutem a temática. Metodologicamente, trata-se de um estudo bibliográfico de natureza qualitativa em que as discussões

\footnotetext{
${ }^{4}$ Art. 26-A. Nos estabelecimentos de ensino fundamental e de ensino médio, públicos e privados, tornase obrigatório o estudo da história e cultura afrobrasileira e indígena.

$\S 2^{\circ}$ Art. 26A, Lei 9394/1996: Os conteúdos referentes à História e Cultura Afro-Brasileira serão ministrados no âmbito de todo o currículo escolar, em especial nas áreas de Educação Artística e de Literatura e História Brasileira.

${ }^{5}$ Com a Lei de Diretrizes e Bases da Educação Nacional de $\mathrm{n}^{\circ} 4.021 / 61$, a filosofia passou a ser uma disciplina complementar no currículo. Já com a LDB de $n^{\circ} 5.692 / 71$, a filosofia foi substituída nos currículos escolares do segundo grau e com a Lei de $n^{\circ}$ $7.044 / 82$ foi incluída no currículo como uma disciplina optativa.
} 
teóricas se basearam nas contribuições dos referidos estudiosos do tema.

\section{Uma prosposta do ensino de filosofia na educação básica}

O ensino de Filosofia nunca foi uma máxima ou mesmo prioridade nos programas de educação. Ao longo da História da Educação, a disciplina Filosofia esteve em segundo plano por não ser considerada uma disciplina voltada para a formação do estudante para questões práticas, tendo seu estatuto de disciplina questionado por não apresentar instrumentos que pudessem possibilitar ao estudante transpor o que se aprende $e$ relacioná-lo com o dia a dia. Havia também o entendimento de que era considerada uma disciplina da elite burguesa, um conhecimento a ser adquirido apenas pelos mais inteligentes e iluminados.

O ensino de Filosofia já havia se deparado com inúmeras dificuldades para ser implementado na escola, algumas dessas dificuldades relacionadas à carga horária reduzida, formação docente inadequada, ausência de capacitação dos profissionais da área, desinteresse (tanto das instituições, quanto dos estudantes de licenciatura em nível médio), bem como a escolha em lecionar somente "História da Filosofia".

As dificuldades descritas correspondem ao modelo de educação básica no qual a disciplina está inserida, mas, para renovarse, há posições contrárias à manutenção desse saber, priorizando sua flexibilização e/ou retirada. Essa é a principal questão a ser enfrentada, haja vista a atual conjuntura de diluição do componente curricular Filosofia nos chamados itinerários formativos em que o estudante opta pela formação em ní- vel médio, construindo um percurso voltado para as disciplinas defendidas como essenciais, tais como português, matemática, exatas e ciências da natureza. As disciplinas das ciências humanas ficam relegadas a segundo plano, tendo carga horária reduzida e com isso deixando de contribuir para a formação crítica dos cidadãos.

No Brasil, embora essa problemática tenha sido solucionada, no sentido de que a presença da disciplina Filosofia tenha caráter obrigatório, ela ainda enfrenta desafios, ora na definição de conteúdos, ora na sua permanência. Desse modo, a Filosofia como disciplina entrou e saiu do currículo por diversas vezes. Em se tratando do ensino de Filosofia surge uma problemática: ensinar o aluno a filosofar? Ou ensinar História da Filosofia? Questões como estas perpassam pelo ato do ensino de filosofia.

Cerletti (2008) mostra que o ensino de Filosofia foi ponto importante da maioria das escolas filosóficas desde a antiguidade, cuja ocupação fez parte da vida de vários filósofos. Porém, a partir da modernidade, o ensino de filosofia passou por um processo de institucionalização. Como se pode observar na fala do autor: "A filosofia passa a integrar os sistemas educativos e, portanto, começa a ocupar um lugar, de maior ou menor importância, nos programas oficias" (CERLETTI, 2008, p. 13). Isso determina que a Filosofia deixasse de estar presa apenas ao mundo dos filósofos e passou a compor o interesse das pessoas comuns.

Dessa forma, o ensino de Filosofia passou a ter um professor que é detentor do saber e do outro lado os estudantes que recebem os conteúdos. Freire (1996) diz que ensinar exige conhecimento, pesquisa, pla- 
nejamento e bom senso do docente em ministrar suas aulas, deve ter um objetivo a ser alcançado para que o professor possa avaliar os discentes e fazer a autoavaliação da sua postura neste processo de ensino e aprendizagem.

A desvalorização da Filosofia na escola é visível, pois boa parte dos estudantes acredita que esse conhecimento não serve "para nada". Na instituição educacional, o paradigma tradicional da educação está presente, o estudante torna-se mero espectador, sendo exigido a este a memorização e reprodução dos conteúdos. Estas visões tradicionais refletem nos docentes, nas suas práticas pedagógicas, na relação com os educandos e como estes veem a escola.

No entanto, o que ocorreu foi uma perda da qualidade do ensino de Filosofia que passou a se restringir ao ensinamento de conteúdos filosóficos, comprometendo o ato reflexivo e criativo. Trabalhar os conceitos da Filosofia, relacionando-os com a realidade dos estudantes é essencial para o fortalecimento da própria disciplina, possibilitando que o estudante compreenda a Filosofia como importante no processo de construção de todo um pensamento.

O professor de Filosofia traz com ele a responsabilidade em despertar no estudante o desejo pela Filosofia. Diante disso é preciso criar artifícios que possam contemplar essa tarefa. Um dos grandes problemas encontrados na sala de aula diz respeito ao modo como as teorias são apresentadas, quase nunca sendo revelado o processo pelo qual se consegue pensar de maneira autônoma e crítica.

Ademais, os estudantes são obrigados a memorizar fórmulas e regras descon- textualizadas, sem vinculação alguma com a práxis, o que tornaria o aprendizado entediante, uma vez que o resultado pronto não possibilita conhecer o caminho trilhado para alcançar o método científico. Pode-se notar na observação feita por Cerletti.

Ensinar filosofia não significa somente transladar os saberes tradicionais da filosofia pela mediação de um professor a um aluno. $\mathrm{O}$ filosofar - ou seja, a filosofia em ato - vai além desse plano da simples repetição. Um ensino de filosofia é filosófico na medida em que aqueles saberes são revisados no contexto de uma aula. Isto é, quando se filosofa a partir deles ou com eles e não quando somente se os repete (histórica ou filologicamente). (CERLETTI, 2008, p. 33 e 34).

A fala de Cerletti (2008) destaca a importância de a Filosofia superar a perspectiva tradicional, sendo possível a partir do momento em que são dadas ferramentas para tal. Um bom professor é aquele que se aprimora, atualizando-se constantemente, criando modos diversos de levar para seus estudantes uma Filosofia que seja "prazerosa". Nesse sentido, não se pode partir do nada, faz-se necessário uma fundamentação filosófica, com base em algum filósofo ou escola filosófica, buscando um norte para um filosofar coerente, não apenas se restringindo a conteúdos programáticos.

Com a promulgação da Lei 11.684/2008, a disciplina de Filosofia tornou-se obrigatória na grade curricular das escolas de ensino médio do Brasil. Esse acontecimento trouxe aos pesquisadores do ensino de Filosofia questões de interesse pe- 
dagógico e político que devem ser refletidas e problematizadas. Na dimensão política é relevante enfrentar as implicações para a Filosofia a partir de sua institucionalização escolar sob a forma de disciplina constante nos documentos oficiais do Ministério da Educação.

A LDB, ao mencionar acerca da Educação Básica, afirma em seu art. 22 "A educação básica tem por finalidades desenvolver o educando, assegurar-lhe a formação comum indispensável para o exercício da cidadania e fornecer-lhe meios para progredir no trabalho e em estudos posteriores". (BRASIL, 1996). Entende-se, sobretudo a partir da lei maior, que a Filosofia tem um importante papel na formação cidadã do estudante, tanto na preparação para o exercício dessa cidadania como na maneira como este deverá praticá-la. A função da Filosofia não consiste em preparar o estudante para $\mathrm{O}$ mundo do trabalho numa perspectiva tecnicista, capitalista, mercadológica. Para além disso, ela considera o aspecto da cidadania $e$ o discute a fim de oferecer ao estudante condições para uma formação ética e intelectualmente autônoma, além de capacitá-lo a compreender os fundamentos científicotecnológicos dos processos produtivos.

Com o retorno da Filosofia ao currículo do ensino médio, o Ministério da Educação elabora o documento "Orientações Curriculares para o ensino médio", a fim de assegurar um melhor desenvolvimento das aulas de Filosofia, além de orientar os professores que certamente não possuem uma formação na área. Elaborou também os PCNs do ensino médio (BRASIL, 2000).

Os Parâmetros são referência de qualidade para os ensinos fundamental e médio com objetivo de subsidiar a elaboração $e$ reelaboração do currículo, tendo em vista um projeto pedagógico em função da cidadania do estudante e uma escola em que aprende mais e melhor. Os $\mathrm{PCNs}$, como uma proposta inovadora e abrangente, expressam o empenho em criar novos laços entre ensino e sociedade e apresentar ideais do "que se quer ensinar", "como se quer ensinar" e "para que se quer ensinar". Os PCNs não são uma coleção de regras e sim, um pilar para a transformação de objetivos, conteúdo e didática do ensino.

No documento, evidenciam-se algumas propostas apontadas que remetem a uma formação de qualidade em Filosofia, sendo condição necessária, mesmo quando não considerável, para criar mecanismo que propicie uma didática filosófica, "prazerosa". Porém, surge uma questão fulcral no contexto atual. Como ensinar Filosofia, quando não se tem uma formação na área? Diante da questão apresentada fica evidente o descaso com a educação pública no país. Dessa maneira, a Filosofia se tornaria uma disciplina apenas para preencher carga horária dos professores, onde qualquer docente das áreas do eixo central poderia assumir a disciplina. Certamente a não valorização da educação é um problema sério no país. Seguindo essa proposta, a Filosofia ensinada nas escolas se torna apenas um objeto para atender a um caráter mercadológico, não abarcando seu objetivo que é contribuir para o exercício do pensar, direcionando os estudantes a desenvolverem-se enquanto sujeitos críticos e reflexivos.

Pensar a Filosofia apenas como um projeto de construção da cidadania seria um equívoco, como dissemos anteriormente. 
Imaginá-la unicamente como responsável pela formação de cidadãos de certa maneira faz-nos pensar em seu caráter identitário, isto é, ela precisa imprimir seu caráter revolucionário, contestador, crítico e, principalmente, libertador. Nessa direção, Cerletti (2008, p. 50) ressalta qual seria o papel da Filosofia: "O ensino de filosofia deveria contribuir, em seu exercício, para fazer dos estudantes agentes críticos capazes de pensar, avaliar $e$ poder decidir da melhor maneira as condições de sua incorporação ao mundo de hoje".

Nesse sentido, o exercício filosófico possui como estímulo o componente da superação dos conflitos, estabelecido democraticamente na sociedade. Tais conflitos surgem no ambiente escolar e deles fazem parte. Nesse aspecto, faz-se necessário a luta pela defesa dos direitos humanos e cidadania, fazendo com que os atores escolares, entre eles professores, estudantes, gestores, compreendam esses temas como fundamentais e devem estar na pauta do ensino de Filosofia, mantendo uma relação com as ciências, as artes e a literatura, fazendo uma reflexão sobre a realidade, a qual está inserida, ou seja, despertar no sujeito o pensamento inovador, crítico e independente, levando-o a pensar coletivamente. $\mathrm{O}$ ensino da Filosofia no ensino médio tem a condição, portanto, de desenvolver no estudante uma "atitude filosófica", ou seja, uma atitude investigativa, interrogativa.

\section{Outras vozes para o ensino de filosofia}

A lei de Diretrizes e Bases da Educação Nacional (LDB) foi modificada pela lei 10.639/03, que tornou obrigatória a inserção no currículo oficial os conteúdos de História e Cultura Afro-brasileira e Africana. A lei garante que tanto na educação básica como na educação superior seja obrigatória a inclusão nos currículos desses referidos conteúdos. Vale ressaltar que o movimento negro ${ }^{6}$ se manteve firme e forte para que a lei fosse sancionada de modo a legitimar a formulação da lei $10.639 / 03$, porém, após cinco anos a lei 11.645/08 altera a lei 10.639/03, abarcando as articulações do movimento dos povos indígenas, como afirma Noguera (2014, p. 17):

As referidas leis constituíram a mudança do artigo 26- A da Lei 9.394/96, a LDB. Portanto, ficou estabelecido que os estudos de História e Cultura Afro-Brasileira, Africana e Indígena são obrigatórios em todas as modalidades de ensino e níveis de educação.

Desse modo, o fortalecimento do cumprimento desta lei se dá no contexto de luta e resistência por políticas públicas em prol da consolidação dos conteúdos de história e cultura Africana e Indígena. Mas como inserir conteúdos obrigatórios relacionados ao ensino da cultura africana sendo que somos levados a estudar por currículos ocidentais, hegemônicos de caráter universal? Como desmitificar a reprodução da imagem

\footnotetext{
${ }^{6}$ Segundo Amilcar Pereira, o referido movimento é compreendido como organizado com um movimento social que tem como particularidade a atuação em relação questão social. Sua formação complexa engloba o conjunto de entidades, organizações e indivíduos que lutam contra o racismo e por melhores condições de vida da população negra, seja através das praticas culturais, de estratégias políticas, de iniciativas educacionais etc.; o que faz da diversidade e pluralidade características desse movimento social. (PEREIRA, 2006, p. 26 apud PONTES, 2017, p. 24).
} 
negra associada apenas à escravidão, desconsiderando sua história?

A lei 10.639/03 traz consigo seu caráter obrigatório justamente para superar essas dificuldades até então impostas, revelandonos que existem outras formas de pensamento que não apenas o ocidental, mas o africano, asiático e demais pensamentos.

Sem dúvida, o estabelecimento do discurso filosófico ocidental como régua privilegiada do pensamento institui uma desigualdade epistemológica. Uma injustiça cognitiva que cria escalas, classes para o pensamento filosófico, estabelecendo o que é mais sofisticado e o que é mais rústico $e$ com menos valor acadêmico. (NOGUERA, 2014, p. 23).

Consoante à fala de Noguera é necessário considerarmos outras vozes e filosofias, de modo que a discussão curricular seja importante e extremamente necessária para uma reformulação dos horizontes políticos $e$ epistemológicos que sustentam a base da construção dos currículos de Filosofia. A lei visa contribuir para o fortalecimento da identidade nacional através do reconhecimento de outras heranças além das europeias na formação cultural e da história brasileira.

Retomando a questão, como desmistificar a reprodução da imagem negra exclusivamente no viés da escravidão dos povos negros? É uma tarefa que requer muito esforço, mas com a lei 10.639/03 esse cenário reprodutivo de que os negros são seres sem pensamento, sem história, foi superada no momento em que houve a modificação curricular em que se buscou valorizar outros aspectos da presença negra no Brasil. Ainda é possível perceber que existe silenciamento em relação ao pensamento africano $e$ afrobrasileiro. Quebrar esse silêncio é uma exigência necessária, pois descolonizar o currículo e pensá-lo sob outra perspectiva implica na mudança de paradigma e de epistemologia.

Uma filosofia descolonizada estaria comprometida em pensar não apenas o local, mas desde o local, pensando estratégias que, atentas ao modo eurocêntrico de produzir conhecimento e filosofia, e teriam as filosofias produzidas na Europa e nos EUA como apenas algumas entre outras formas de produzir a filosofia, o que ampliaria o aspecto da discussão sobre modos de produção filosófica. (NASCIMENTO, 2012, p. 80).

Nesse sentido, é preciso descolonizar o pensamento, permitir que outros olhares sejam considerados visando a pluralidade de pensamentos existentes para superar a polêmica acerca da existência de uma "filosofia africana" (NASCIMENTO, 2012). Renato Noguera (2014) aborda as diversas razões e concepções que tornaram/tornam o conhecimento produzido na Europa a principal $e$ legítima fonte de conhecimento humano.

Desse modo, Noguera $(2014)^{7}$, destaca a importância de evidenciar os pensamentos acerca do conhecimento da filosofia africana no sentido de combater a desvalorização destes pensamentos. Em contraparti-

\footnotetext{
${ }^{7}$ Renato Noguera é doutor em Filosofia pela Universidade Federal do Rio de Janeiro (UFRJ). Professor do Departamento de Educação e Sociedade da Universidade Federal Rural do Rio de Janeiro (UFRRJ), além dos programas de Pós-graduação em Educação $e$ em Filosofia, atua na universidade como pesquisador do laboratório de Estudos Afro-Brasileiros e Indígenas (Leafro) e coordenador do grupo de pesquisa Afroperpectivas, Saberes e Interseções (Afrosin).
} 
da, a supervalorização dos conhecimentos tidos como genuinamente filosóficos nos quais se localizam na Europa, que é a desumanização juntamente com a zoomorfização ${ }^{8}$ dos africanos, nas quais tentam justificar o desprezo e a desqualificação que o racismo anti-negro se pauta como podemos observar no exceto abaixo:

O crivo eurocêntrico para o conhecimento recusa a validade das justificativas feitas a partir de referenciais não europeus, quer sejam eles filosóficos, culturais, históricos, ou científicos, distinguindo o que é conhecimento válido e o que não é conhecimento. De tal maneira que para preencher os critérios filosóficos específicos que diferenciem a filosofia de outros modos de saber, uma construção intelectual precise estar sempre articulada, ou mantendo algum tipo de diálogo, com pressupostos e temas erigidos pelos gregos. (NOGUERA; DUARTE; RIBEIRO, 2019, p. 08)

Desta forma, os autores elucidam que essa desqualificação dos conhecimentos advindos da África antecede ao período da escravização. $\mathrm{O}$ que nos faz refletir sobre o consenso que nos aponta a Colonização da América enquanto ponto de partida para o surgimento do racismo anti-negro, ao passo que levanta dados históricos imprescindíveis para refletir e repensar as questões que circundam a marginalização da Filosofia Africana e, consequentemente, afro-brasileira. Lança luz à problemática da própria condição desumana que o povo africano foi submetido.

\footnotetext{
${ }^{8}$ A zoomorfização foi responsável pela desclassificação da produção intelectual africana.
}

Nesse prisma, Noguera (2014) denuncia a hierarquização imposta para o resto do mundo em que coloca a Europa hierarquicamente como centro, superior e elevada, enquanto a África, dentro da lógica eurocêntrica, é desprovida de civilidade e em certa medida de racionalidade. Nesse sentido, a Filosofia atravessa os aspectos da colonialidade, uma vez que exclui de forma sistemática todo o conhecimento oriundo dos povos indígenas e de uma forma mais perversa, dos africanos, já que coloca como pseudosaberes ou simplesmente crenças, todo o conjunto de pensamento filosófico. $\mathrm{E}$ isso se caracteriza como racismo epistemológico, pois coloca o pensamento europeu acima de todo e qualquer conhecimento manifestado por esses povos.

Sendo assim, racismo epistêmico remete a "um conjunto de dispositivos, práticas e estratégias que recusam a validade das justificativas feitas a partir de referenciais filosóficos, históricos, científicos e culturais não ocidentais" (NOGUERA, 2014, p. 27). Nesse sentido, não europeu. Isto é, o projeto epistemológico moderno estabeleceu critérios para demarcar e validar o que é conhecimento e o que não é.

As populações negras pertencem ao segmento mais pobre da população e que não há uma relação direta entre sua situação socioeconômica atual. O lugar social de destaque ocupado pelo negro na sociedade pode ser considerado como uma ausência de lugar, daquele que é silenciado e apagado nos diversos espaços sociais em que o branco ocupa situação de destaque, de forma que o negro não seja reconhecido como um sujeito histórico, social e cultural, abrindo-se um abismo entre negros e brancos em nossa 
sociedade, como pode ser analisada na citação a seguir:

$\mathrm{O}$ abismo racial entre negros $e$ brancos no Brasil existe de fato. As pesquisas científicas e as recentes estatísticas oficiais do Estado brasileiro que comparam as condições de vida, emprego, saúde, escolaridade, entre outros índices de desenvolvimento humano, vividos por negros e brancos, comprovam a existência de uma grande desigualdade racial em nosso país. Essa desigualdade é fruto da estrutura racista, somada a exclusão social $e$ a desigualdade socioeconômica que atingem toda a população brasileira $e$, de um modo particular, o povo negro. (GOMES, 2005, p. 47).

Conforme Gomes o abismo existente traz desigualdades que impactam a vida dos povos negros, de modo a diferenciá-los economicamente e socialmente. De uma maneira específica, o racismo epistêmico sustenta a produção de um único saber válido e filosófico que se dá geograficamente na Europa.

Uma tese geral que reafirma o eurocentrismo e o racismo epistêmico na Filosofia é justamente a sustentação de que o nascimento das manifestações filosóficas teve origem e desenvolvimento tão somente na Europa e de forma específica na Grécia Antiga. Dentro desse contexto, é possível estabelecer uma geopolítica para a Filosofia além das fronteiras europeias? É claro que sim, no entanto, é preciso desconstruir todo racismo epistêmico que inclusive muitos filósofos o sustentaram com uma visão que descaracteriza o pensamento africano $e$ o seu povo. Há alguns exemplos como Kant, Hegel, Hume e Voltarie. O racismo expresso por eles não pode anular seus trabalhos $e$ suas contribuições, no entanto, é preciso levar em consideração o racismo epistêmico e seus desdobramentos sobre suas obras. $\mathrm{O}$ que temos aqui é um epistemicídio, pois anula, desqualifica, "mata" qualquer conhecimento que não seja oriundo da Europa, negando-lhe um lugar de existência.

Neste sentido, o autor propõe que a Filosofia reexamine a sua geopolítica, afinal é uma característica própria da Filosofia não aceitar ideias prontas sem fazer diante delas um exame minucioso, pois a questão do nascimento da filosofia enquanto paradigma propriamente europeu está marcado pelo racismo epistêmico. A proposta de Noguera (2014) é justamente colocar em evidência a necessidade de se fazer a dissolução dessa geopolítica hegemônica, colocando a África de forma equânime ao que concerne a produção de conhecimento humano de maneira plural e descolonizada.

\section{Existe uma filosofia africana?}

Com base em pesquisa bibliográfica $e$ análise das legislações, iniciamos as discussões acerca da existência da filosofia africana $e$ as demarcações da Filosofia com uma crítica contundente, que destaca o quanto esta área de conhecimento humano é solo permeado pelo racismo institucionalizado ao colocar à margem todas as manifestações filosóficas que outros povos realizaram, descaracterizando de forma substancial essas filosofias.

Neste sentido, os autores ressaltam o quanto a Filosofia ainda nos dias de hoje produz poucos debates e reflexões no que diz respeito ao racismo e a existência de uma filosofia Africana e toda uma configuração 
que permitiu/permite a sua consolidação tanto na sociedade quanto nas áreas de produção de conhecimento, especialmente na Filosofia.

Ao avançar na análise, examinamos a própria constituição da Filosofia, que por vezes se caracteriza enquanto um saber sofisticado e elevado que acaba por se distanciar na maioria das vezes da realidade circunscrita, afirmando em vários momentos a existência apenas de uma filosofia ocidental, mostrando incertezas da existência de uma filosofia africana. Com essa natureza, a Filosofia se distancia do cotidiano e esse aspecto pode ser considerado também enquanto uma razão da área não se debruçar de forma recorrente às questões que perpassam as relações étnico-raciais e culturais.

Para dar ainda mais ênfase e subsídio a esta crítica, podemos nos pautar na quantidade de investigações no campo da Filosofia sobre as relações étnico-raciais, pouco difundidas e reveladas sobre o quanto a Filosofia aqui no Brasil ainda está impregnada por uma visão de mundo eurocêntrica, já que são encontradas poucas pesquisas que contemplam as relações étnico-raciais ou a filosofia africana.

Sendo assim, para tocar no cerne da questão e entender os motivos pelos quais quase não há investigações filosóficas que abarquem os temas étnico-raciais, estudiosos vem aos longos dos anos buscando por meio de estudos, reflexões e pesquisas a comprovação da existência de uma filosofia africana.

Desta maneira é perceptível que exista uma filosofia africana, que fora esquecida e negada por muito tempo, no intuito de prevalecer apenas a existência de uma filoso- fia ocidental. Assim, fica evidente através das leituras e pesquisas que há uma lacuna nos assuntos que versam sobre a história e cultura afro-brasileira e africana.

Dentro deste cenário, é preciso pensar tais estudos para o ensino de Filosofia, para assim, investigar, refletir e produzir filosoficamente trabalhos que contemplem temas tão importantes e necessários para a promoção de um ensino de Filosofia que contribua de forma efetiva para as relações étnicoraciais e para a desconstrução de um conhecimento seletivo e eurocêntrico.

Voltando a pergunta, é possível Filosofia além da Europa? Sim, desde que se supere essa visão unilateral e eurocêntrica, construindo assim, uma filosofia pautada na perspectiva pluralista do conhecimento epistêmico. Ainda que hajam filósofos que discutiram a questão do racismo anti-negro, ainda assim não deixaram o terreno do eurocentrismo. Na maioria das universidades, a Filosofia se dá somente por três vias, a saber: a conceitual, a analítica e a pragmática. Embora hajam outros tantos caminhos para efetuar uma investigação filosófica.

Salientamos que a Filosofia Africana deve ser valorizada em pé de igualdade com outras produções filosóficas. Segundo Renato Noguera (2014), alguns outros filósofos influenciaram na concepção e reflexão de uma epistemologia antirracista e que retira da Europa o mérito de validação de conhecimento.

O trabalho desse filósofo é imprescindível para desnaturalizar a posição hegemônica da Europa enquanto produtora e detentora de um conhecimento válido e único. Neste sentido, o que se deve propor é que a filosofia reexamine a sua geopolítica, afinal é 
uma característica própria da filosofia não aceitar ideias prontas sem fazer diante delas um exame minucioso. Em contrapartida, entender porque um conhecimento considerado válido e genuíno e que é produzido pelos africanos é deslegitimado de uma forma tão perversa pelos ocidentais.

A questão do nascimento da Filosofia enquanto paradigma propriamente europeu está marcado pelo racismo epistêmico. A prática da tradição ocidental se perpetua até os dias atuais de modo que os filósofos profissionais da academia são eurocêntricos, mesmo tendo o conhecimento da Lei 10639/03 onde diz que além da educação básica os conteúdos também deverão ser discutidos obrigatoriamente no ensino superior. Portanto, reproduz a tradição da filosofia analítica, de certo modo a tentar fazer da filosofia quase uma ciência exata, em que às cosmovisões africanas $e$ indígenas não têm voz, de modo a serem subalternizadas. Isso fica mais evidente na citação a seguir:

Infelizmente, devido à ausência de registros escritos nos últimos tempos, às reflexões filosóficas de alguns pensadores não têm sido preservadas efetivamente. De fato as reflexões filosóficas de pensadores africanos não foram preservadas ou transmitidas através de relatos escritos; a verdade é que esses filósofos continuam desconhecidos entre nós. (OMOREGBE, 1998, p. 5)

Nota-se que o proposto acima evidencia a recusa de que os povos africanos são produtores de conhecimento válido, ou seja, invalida os percursos intelectuais de povos que foram historicamente subalternizados pelas relações de colonização. Complementamos com a afirmação a seguir:
Na prática, esta disposição filosófica do ser é experimentada como a exclusão dos outros, que não aparecem como sendo o mesmo que nós, ou que são percebidos como uma ameaça á mesmice inscrita em nossa particularidade. Esta lógica de exclusão foi experimentada historicamente, como foi para nós, na cristianização $e$ colonização dos outros povos do mundo. (RAMOSE, 2011, p. 11)

Segundo o autor, precisamos combater a injustiça cognitiva, a falta de reconhecimento de que todos os povos produziram $e$ produzem conhecimentos. A filosofia deve partir de uma ideia pluriversal e não eurocêntrica como se tem feito. Ratificamos essa perspectiva na citação a seguir.

Os conquistadores da África durante as injustas guerras de colonização se arrogaram a autoridade de definir a filosofia. Eles fizeram isso cometendo o epistemicídio, ou seja, o assassinato das maneiras de conhecer e agir dos povos africanos conquistados. (RAMOSE, 2011, p. 9)

É perceptível como a filosofia africana era tida como algo menor, ou seja, os lugares de fala dos povos africanos foram silenciados e negados, para que apenas a filosofia ocidental tivesse vez e voz por muitos anos, portanto, é necessário que não valorizemos somente a cultura ocidental, mas que possamos dialogar, divulgar e inserir a filosofia africana nos nossos estudos e promover o pensamento pós-colonial, ou seja, construir o processo de descolonização intelectual para uma filosofia libertária.

Existe, de fato, uma filosofia africana, mas que hoje ainda é pouco conhecida. Considerando os elementos supracitados é 
sabido que a filosofia ocidental e sua forma de argumentação não devem ser tomadas como padrão para se produzir um pensamento. Torna- se necessário que façamos o exercício de discutir e divulgar a filosofia africana para que todos tenham acesso e se apropriem desse pensamento para promover a reflexão e a libertação.

Ademais, a tarefa da Filosofia é libertar o pensamento, sair da caixinha e dos formatos pré-estabelecidos. Essa realidade deve ser o principal motivo para se discutir na educação básica, principalmente com os estudantes do ensino médio, a existência de outros saberes e pensamentos, teorias e filosofias diferentes das que estão acostumados, apresentando-lhes cosmovisões de vida e de mundo diferentes.

Para o professor de Filosofia, urge pensar nessas filosofias, levá-las para a sala de aula, objetivando instrumentalizar os estudantes com conhecimentos de outros povos que sempre estiveram negados e silenciados no currículo escolar. Talvez seja este o maior desafio a ser encarado pelos profissionais da Filosofia, desmistificar preconceitos e estereótipos relacionados aos povos africanos tanto para os colegas quanto para os estudantes e, principalmente em sua própria formação.

É sabido que a maioria dos professores de Filosofia não teve em sua formação inicial oportunidade de aprofundamento a respeito da filosofia africana, sobretudo porque os cursos de licenciatura em sua maioria privilegiam um currículo cujas disciplinas são voltadas para a tradição filosófica. Com isso não queremos afirmar que a tradição não seja importante, haja vista que é a constituição da filosofia ocidental. O que se questio- na é a permanência de um discurso conservador em detrimento de saberes tradicionais de outros povos que também produzem conhecimentos.

Desse modo, a discussão acerca do ensino de filosofia na educação básica, especificamente no ensino médio, deve ser compreendida como possibilidade de ampliação de repertório filosófico africano. Certamente, o conhecimento dessas filosofias contribui significativamente para a formação de nossos jovens, principalmente oportunizando que estes possam se reconhecer enquanto sujeitos históricos, protagonistas da própria vida, identificando-se cultural e epistemologicamente com a história da África e da cultura afro-brasileira, haja vista termos nas escolas públicas brasileiras uma presença efetiva de jovens negros.

\section{Considerações finais}

A partir dos elementos discutidos é necessário entender o ensino de filosofia como uma ferramenta importante no enfretamento a práticas racistas no espaço educacional. Nesse sentido, a filosofia caminha para a produção de conhecimentos antirracistas possibilitando a crítica aos locais de subalternização histórica a que os negros foram colocados. Percebemos que a lei 10.639/03 precisa ser mediadora nesse diálogo. Por se tratar de um marco legal obrigatório, compete também aos professores, gestores e demais atores envolvidos no processo educativo a responsabilidade de incluí-la no currículo, permitindo que o estudante conheça sua história.

É justamente nesse ponto que se inicia o papel da Filosofia. Pensar em uma educação construída em prol da diversidade 
em que se assegure o acesso e a permanência dos diferentes grupos étnicos ao sistema educacional, superando a existência de uma visão eurocêntrica como sendo a única a orientar a elaboração dos arranjos curriculares. $\mathrm{O}$ ensino de Filosofia deve refletir sobre alternativas metodológicas de ensinoaprendizagem, contrariando o modelo tradicional de educação, promovendo atos que estabeleçam posições de resistência em favor das multiplicidades, criando novas possibilidades de abertura e formas de se fazer educação.

Desse modo, a Filosofia deve prezar por um ensino pluriversal, considerando a existência de uma filosofia africana, indígena etc. Quando optamos por discutir acerca das relações étnico-raciais, filosofia africana, história e cultura afro-brasileira, tendo como ponto de partida os marcos legais, foi no sentido de promover um debate em torno da consolidação de um currículo que seja plural, abarcando todas as culturas, saberes, tradições, conhecimentos de diversos povos $e$ filosofias.

\section{Referências}

BRASIL. Lei n. 10.639/03, de 9 de janeiro de 2003. Altera a Lei no 9.394, de 20 de dezembro de 1996, que estabelece as diretrizes e bases da educação nacional, para incluir no currículo oficial da Rede de Ensino a obrigatoriedade da temática "História e Cultura AfroBrasileira", e dá outras providências. Disponível em: http://www.planalto.gov.br/ccivil_03/leis/2003/110.639.htm. Acesso em: 27 maio. 2020.

BRASIL. Lei $n^{\circ}$ 11.684: inclui a Filosofia e a Sociologia como disciplinas obrigatórias nos currículos do ensino médio. Brasília, 2 de junho de 2008. Disponível em: http://www.planalto.gov.br. Acesso em: 03 jun. 2020.

BRASIL. Lei de Diretrizes e Bases da Educação Nacional. Lei n ${ }^{\circ}$ 9.394, de 20 de dezembro de 1996, Biblioteca Digital da Câmera, Disponível em: http://bd.camara.leg.br. 8. ed. 2013. Acesso em: 27 maio. 2020. fia tem como desafio fazer a conexão entre problema social do racismo, propondo relações conteúdo/linguagem e a construção social de um diálogo nas escolas sobre a imtões como: identidade, ancestralidade, pertencimento de um povo ao seu território, além de fazer um apanhado geral sobre os problemas enfrentados pelas populações negras no país.

Trabalhar essas questões é imprescindível para se conhecer efetivamente a história dos povos africanos. Nessa perspectiva, a Filosofia propicia a desconstrução de preconceitos que ainda estão fortemente presentes na sociedade. Diante do exposto, reafirmamos veementemente a importância se outras vozes serem legitimadas, reconhecidas e valorizadas no currículo escolar, permitindo que nossos jovens tenham acesso a variados saberes construídos ao longo de milênios e que são patrimônio da humanidade. emoção e razão, direcionando o olhar para o portância da cultura africana. Debater ques- 
BRASIL. Ministério da Educação, Secretaria de Educação Básica. Orientações curriculares para o ensino médio, vol. 3, 2006. Disponível em: www.portal.mec.gov.br/cne/arquivos. Acesso em: 01 jun. 2020.

BRASIL. Ministério da Educação. Secretaria de Educação Básica. Orientações Educacionais Complementares aos Parâmetros Curriculares Nacionais. Ciências Humanas e suas Tecnologias. Brasília, DF, 2006. Disponível em: http://portal.mec.gov.br/seb/arquivos/pdf/book_volume_03_internet.pdf. Acesso em: 02 jun. 2020.

CERLETTI, A. O ensino de filosofia como problema filosófico. Belo Horizonte: Autêntica, 2008.

FREIRE, Paulo. Pedagogia da autonomia: saberes necessários à prática educativa. São Paulo: Paz e Terra, 1996.

GOMES, N. L. Alguns termos e conceitos presentes no debate sobre relações raciais no Brasil: uma breve discussão. In: Educação anti-racista: caminhos abertos pela Lei Federal $n^{\circ}$ 10.639/03. Brasília-DF: MEC/SECAD, 2005.

PONTES, K. R. Kemet, escolas e arcádeas: a importância da filosofia africana no combate ao racismo epistêmico e a lei 10.639/03. 2017. 93f. Dissertação (Mestrado) - Centro Federal de Educação Tecnológica Celso Suckow da Fonseca, Rio de Janeiro, 2017.

NASCIMENTO, W. Outras vozes no ensino de filosofia: o pensamento africano e afrobrasileiro. Revista Sul-Americana de Filosofia e Educação. n. 18: maio-out/2012, p.74-89.

NOGUERA, R. O ensino de filosofia e a Lei 10.639. Rio de Janeiro: Pallas, 2014.

NOGUERA, R.; DUARTE, V.; RIBEIRO, M. dos S. Afroperspectividade no ensino de filosofia: possibilidades da Lei 10.639/03 diante do desinteresse e do racismo epistêmico. O que nos faz pensar. v. 28, n. 45, p. 434-451, 2019.

OMOREGBE, J. I. A filosofia africana: ontem e hoje. Tradução de Renato Nogueira Jr. African Philosophy: Yesterday and Today in African Philosophy: an Anthology by Emmanuel Chukwudi Eze, Massachusetts/Oxford, Blacwell Publishers, 1998. Disponível em: https://filosofia-africana.weebly.com/uploads/1/3/2/1/13213792/joseph_i._omoregbe__filosofia_africana._ontem_e_hoje.pdf. Acesso em: 27 maio. 2020.

RAMOSE, M. B. Sobre a Legitimidade e o Estudo da Filosofia Africana. Tradução de Dirce Eleonora Nigro Solis, Rafael Medina Lopes e Roberta Ribeiro Cassiano. Revisão de Dirce Eleonora Nigro Solis. Ensaios Filosóficos, vol. IV, outubro/2011.

Recebido em: 22/07/2020 Aprovado em: 19/10/2020 